\title{
Multilevel Collapsibility of Loess under Irrigation in Jinya Town, Gansu Province, China
}

\author{
Xiaozhou Zhang, ${ }^{1,2}$ Yudong Lu $\mathbb{D}^{1,2}$ Xin Li, ${ }^{1,2}$ Yangchun Lu, ${ }^{1,2}$ Jianzhong Sun, ${ }^{1,2}$ \\ and Wangsheng Pan ${ }^{1,3}$ \\ ${ }^{1}$ College of Environmental Science and Engineering, Chang'an University, Xi'an 710054, China \\ ${ }^{2}$ Key Laboratory of Subsurface Hydrology and Ecology in Arid Areas, Chang'an University, Ministry of Education, \\ Xi'an 710054, China \\ ${ }^{3}$ School of Tourism and Resources Environment, Qiannan Normal University for Nationalities, Duyun 558000, China
}

Correspondence should be addressed to Yudong Lu; luyudonga@chd.edu.cn

Received 27 May 2019; Revised 11 August 2019; Accepted 27 August 2019; Published 13 October 2019

Academic Editor: Kirk Hatfield

Copyright (c) 2019 Xiaozhou Zhang et al. This is an open access article distributed under the Creative Commons Attribution License, which permits unrestricted use, distribution, and reproduction in any medium, provided the original work is properly cited.

\begin{abstract}
The collapsibility of loess has constantly been a major problem in engineering geology. The determination of the collapsibility process and characteristics of loess are crucial to foundation construction and residents' life in the Loess Plateau. Thus, a largescale in situ irrigation collapse experiment was conducted on a $10 \mathrm{~m}^{2}$ test pit. A total of 79 benchmarks are used in this experiment. These benchmarks are divided into three categories, namely, deep-buried steel pipe benchmarks, ground benchmarks inside the pit, and ground benchmarks outside the pit. The irrigation and observation time spanned 40 days. In the entire irrigation experiment, a three-day water suspension period resulted in two peaks on the collapsibility velocity curve, thereby showing a remarkable difference in the collapsibility curve from the standard one. In terms of the microstructural deformation types of loess and infiltration process of irrigation water, we found that the collapsibility of loess is a dynamic process apart from being particularly sensitive to water. That is, even after a full collapse of the irrigation process, new pores will eventually form once the water content in the loess begins to decline, thereby providing conditions for another loess collapse. Therefore, multilevel collapsibility can occur during continuous irrigation, which is a problem that has been unexplored in previous applications.
\end{abstract}

\section{Introduction}

Loess is a special engineering geological material but has been found to collapse during the humidification process because of its open metastable structure [1,2]. These porous materials, which are bonded to silt and sand particles by clay particles, exhibit different properties from other materials $[3,4]$. Under dry conditions, loess can maintain a favorable upright position [5], even at a steep slope of approximately $90^{\circ}$; however, this material will collapse under its own weight or under load once immersed in water [6]. A collapse can cause a series of problems and huge financial losses to infrastructure projects on collapsible loess soils and collapse-induced geological hazards [7]. For example, slope failure and cracking caused by a collapse in the South Jingyang Plateau have considerably reduced the arable land in the area since 1976 [8], and over 300 buildings have been destroyed [9].

Research on the collapsibility of loess can be traced back to the 1940s [10], and these studies have been conducted with the requirements of infrastructure construction and progress of science and technology. Initially, in some studies, scholars summarized several properties of collapsible loess to meet the needs of simple engineering construction according to macroscopic test and experience. Collapsible loess was divided into two types, namely, gravity and nongravity collapsible loess in accordance with its causes, properties, and deformation characteristics [11]. On the basis of relative wetting coefficient, loess can also be divided into three grades, namely, slight, medium, and strong collapsible-prone loess [12-14]; however, the composition, pore 
types, and mineral composition of loess particles have been rarely studied owing to the backward means of observation [15-17]. After the 1970s, the study of loess has been gradually transferred to a microstructure through scanning electron microscopy (SEM) in loess research. Several studies have provided various summaries of loess microstructure through diverse means and classified the contact mode, pore size, and type of loess particles. Lei [18], Gao [19], and Barden et al. [4] proposed a perspective that classifies the particles into sand grain, silt grain, and clay particle. They divided the pores into four types (i.e., macro, spaced, intergranular, and intragranular pores) on the basis of the particle contact mode. Accordingly, existence of these pore types provides the conditions for the transformation between the pore types and loess collapse. The development of software technology has resulted in an increasing number of research studies focusing on the quantitative study of collapsible loess. Image analysis software applied to the medical field was introduced for the quantitative analysis loess images. In particular, ImageJ and Image-Pro Plus have been the most frequently used tools for measuring the shape parameters of sand grains (i.e., polygon area, max or mix diameter, and Feret size) [20-22]. Other studies have obtained similar results by using non-image processing software, such as MATLAB [23]. Several mathematical methods have been applied to loess mineral identification and effectively functioned [24, 25]. Accordingly, many mechanisms of loess collapsibility have been proposed on the basis of the previous quantitative and qualitative research results. Scholars and experts have generally accepted the following standpoint: loss of capillary tension $[10,16,26]$, solution of soluble [11, 27], shortage of clays [28], and under compaction [26, 29-31]. Elastoplastic modeling and other approaches based on the concepts of elastoplastic or natural loess tests can interpret the reason for loess collapse and be used as a tool for predicting the volume change in collapsible loess in a certain situation [32].

Some studies have analyzed the saturated collapsibility of loess and the deformation characteristics of special soil under special conditions. Sillanpää found that the cycles of wetting and drying in silty clay loams result in an increase in the mean weight diameter (M. W. D.) of large aggregates and the cycles of freezing and thawing water contents near saturation lead to a decrease in M. W. D. of large aggregates [33]. Chamberlain believed that the dynamic change of clayey silt and silt clay structure will occur during the freezing and thawing process $[34,35]$. Key et al. indicated that the tensile strength and shear strength of aggregates are dynamic properties and that the strength will change during the freezing and thawing or wetting and drying process [36-39]. Such dynamic changes in structure and strength will lead to dynamic changes in the stability of natural loess [40]. However, only a few studies have been conducted on the change in loess structures and whether the loess that had already collapsed continues to undergo a change in volume when it encounters water again. Therefore, the multilevel collapsibility of loess is determined by irrigation test, and the causes of multilevel collapsibility are analyzed in a microscopic scale using SEM.

\section{Materials and Methods}

2.1. Location and Climate. Jinya Town is a crucial courier station on the ancient Silk Road. This town is located east of Lanzhou city and west of Yuzhong County and is only $18 \mathrm{~km}$ from Lanzhou and $20 \mathrm{~km}$ from the county seat (Figure 1). Jinya Town, resulted from the long and narrow terrain of Gansu Province, serves as a transportation junction for the Lanzhou and Longzhong regions. In addition to the Lanzhou-Lianyungang Railway and China National Highway 309, Chan-Liu highway and Baoji-Lanzhou High-Speed Railway Double line are nearly being opened to traffic and pass through the town. The Wanchuan River, which is a tributary of the Yellow River, flows through the territory from east to west. Since the Quaternary Period, the Loess Plateau has been intermittently uplifted owing to the Qinghai-Tibet Plateau, and the Yellow River and its tributaries have been cut down continuously, thereby forming a multilevel terrace that accepts loess deposition. The multilevel terrace has become a loess-covered terrace that spreads along the two sides of the river, with flat and open terraces. The Wanchuan River terrace is a typical example. The land on the south side of the river is relatively broad and extensively known for cauliflower, broccoli, celery, and tobacco grown in the area. By contrast, the north side of the river has limited land but with numerous industrial enterprises and is an important plastic manufacturing base in Gansu Province.

Jinya Town is situated in the temperate zone and enjoys a semiarid climate with hot summers and cold dry winters. The monthly $24 \mathrm{~h}$ average temperature ranges from $-5.8^{\circ} \mathrm{C}$ in January to $21.4^{\circ} \mathrm{C}$ in July. The mean annual temperature is $9.1^{\circ} \mathrm{C}$, while annual rainfall is $400 \mathrm{~mm}$, nearly all of which falls from May to October.

2.2. Basic Physical Properties of Loess. The experimental site was selected from the Jinjiaya village farmland, which is on the third terrace of the Wanchuan River. Figure 2 shows that this third terrace of the Wanchuan River is $60-70 \mathrm{~m}$ above the river surface. The upper part of this terrace is approximately $30 \mathrm{~m}$ thick Malan loess formed in the upper Pleistocene of the Quaternary, the middle part is approximately $15 \mathrm{~m}$ thick interlayer of Lishi loess and Paleosoil, and the bottom part is a thick sand and gravel layer formed by alluviation and diluviation of the middle Pleistocene of the Quaternary. Previous studies combined with optical stimulated luminescence dating and carbon-14 dating showed that the formation age of the lowest layer of loess on the third terrace was not earlier than $54.41 \pm 4.89 \mathrm{ka}$ [41]. The samples were obtained by the artificial vertical excavation of exploration well with a diameter of $1.0 \mathrm{~m}$ and depth of $5.1 \mathrm{~m}$. After removing $30 \mathrm{~cm}$ of topsoil and cultivated soil on the surface, a group of soil samples were taken at intervals of $60 \mathrm{~cm}$ and 9 layers of soil samples were obtained in the $5.1 \mathrm{~m}$ deep exploration well. Each layer of soil sample contains 4 ring knife samples for measuring the collapsibility coefficient, 1 ring knife sample for measuring permeability, 1 ring knife sample for scanning under SEM, 3 aluminum box 


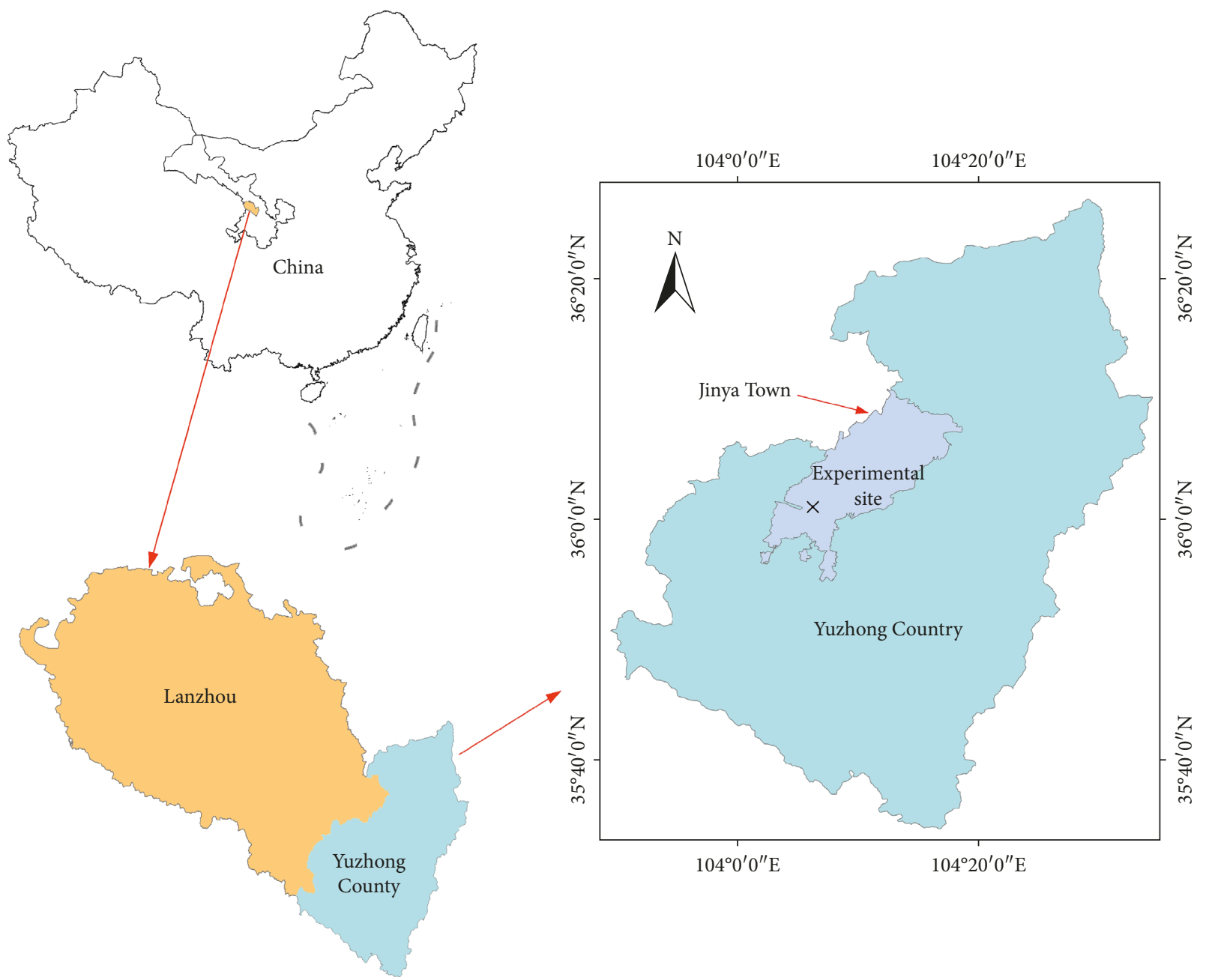

FIgURe 1: Location map of experimental site in Jinya Town, Yuzhong County, Lanzhou, Gansu Province, China.

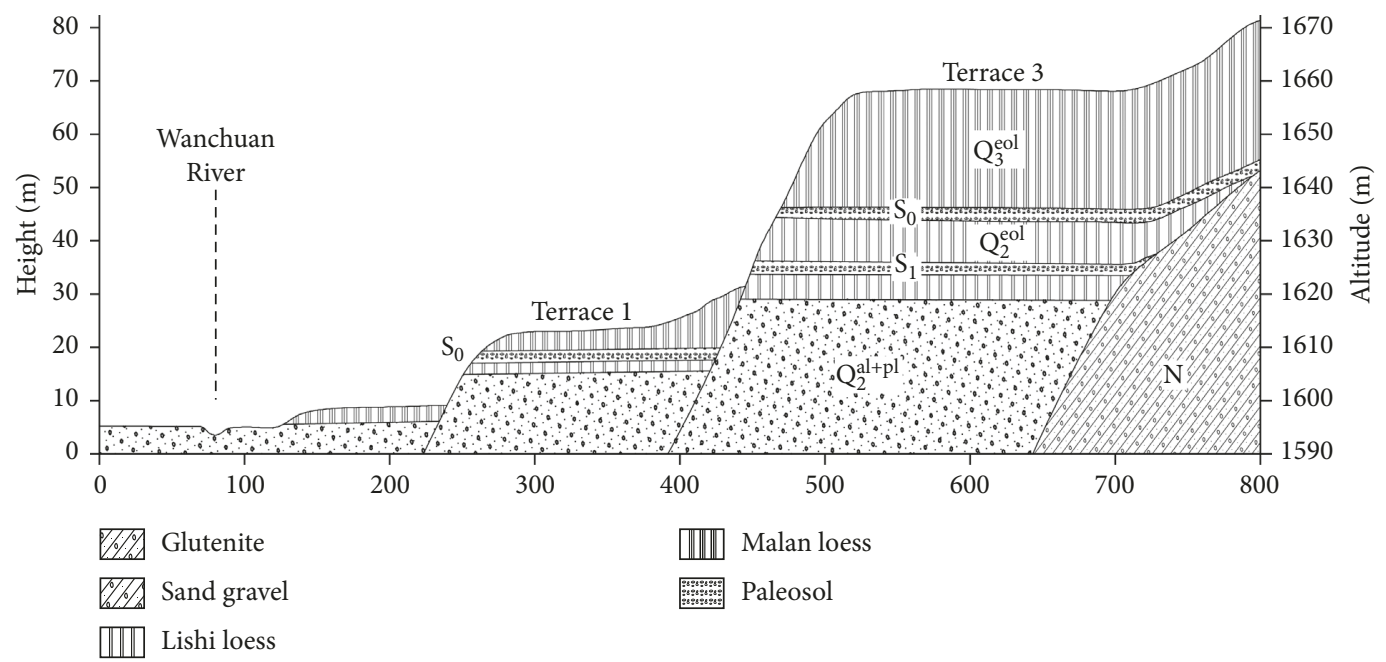

Figure 2: Terrace profile of Jinya Town, Wanchuan River (modified by Hu et al. [41]). On the right bank of the Wanchuan River is a typical stacked terrace. The experimental site is located on terrace 3, which is flat and open and covered with collapsible Malan loess thicker than $30 \mathrm{~m}$.

samples for measuring the water content and specific gravity, and $200 \mathrm{~g}$ of loose soil samples for measuring the liquid limit and plastic limits.
The particles, which are typical representative of the silt Malan loess zone, are evenly distributed and well sorted. The loess grading is determined with a laser particle size 
distribution instrument (Dandong Bettersize 2000) in the geological engineering laboratory of Chang'an University. The particles within the $5.1 \mathrm{~m}$ deep artificial exploratory well are mainly composed of silt, followed by sand (approximately $29 \%$ content) and clay (generally below $10.5 \%$ content) (see Figure 3). This combination of particles may easily form porous media because of the presence of many large particles and the pore structure is generally unstable. Under a dry condition, the loess is pale gray yellow, lumplike, and can withstand high pressure without being damaged, although it is mainly composed of silt. Under a wetting or soaking condition, the strength and cohesion of dark brown loess decline sharply. This type of loess can be crushed by hand with minimal pressure and is easy to disperse during sample preparation, thereby resulting in failure.

Table 1 shows that the soil water content obtained in an oven (DHG-9420A) fluctuates at approximately $17 \%$ in the $5.1 \mathrm{~m}$ deep range after rain one day before sampling. The result of this small change shows the uniformity of soil particle distribution in this area and the considerable permeability of loess, which are confirmed by subsequent permeability tests. The dry density of loess slightly changes only with an increase in depth, which is maintained at $1.35 \mathrm{~g} /$ $\mathrm{cm}^{3}$. The specific gravity of loess measured using the pycnometer method with kerosene as medium ranges from 2.735 to 2.944 , which is higher than that of the fine grain loess in the east. The liquid and plastic limits are approximately 30.1 and 19.2, respectively, and the liquid limit tends to decrease with depth. We performed an indoor collapsibility experiment on 20 ring knife samples made in the field and calculated the collapsibility coefficient of each layer of loess using the double-line method (model WG single-lever consolidometer: triple high pressure). The collapsibility coefficients of all ring knife samples are greater than 0.015 (see Table 1). These results verify that the loess in this region has typical collapsibility. Loess funnel and loess collapsible pit of approximately $3 \mathrm{~m}$ in diameter are frequently observed on the Loess Plateau surface.

The uniformity and continuity of soil are evidently represented by the uniformity coefficient $(\mathrm{Cu})$ and curvature coefficient (Cc). In the Malan loess in Jinya Town, the $\mathrm{Cu}$ and $\mathrm{Cc}$ values are 8.30 and 1.69, respectively. From an engineering viewpoint, this soil is well graded $(\mathrm{Cu} \geq 5$, $\mathrm{C} c=1 \sim 3)$. The characteristics of loess are mainly composed of silt particles, loose structure, and favorable permeability. These characteristics may facilitate the immersion of water into the loess depths under continuous rainfall or sufficient irrigation and form a large-scale collapsibility phenomenon. These occurrences cause considerable disturbance to local residents' life and production and reflects a normal order.

2.3. Experimental Settings and Observation. The majority of the previous studies have been focused on the primary saturation collapsibility of loess, but no further research has been conducted on the saturated loess $[42,43]$. In Jinjiaya village, the farmland still remains collapsible loess after perennial flood irrigation. On this basis, we arranged a large test pit on the farmland of Jinjiaya village to observe the deformation of loess in a state of full water.

The code for building construction in collapsible loess regions in China (GB-50025-2004) was used as basis to design the test pit as a square with a side length of $10 \mathrm{~m}$ and a depth of $0.5 \mathrm{~m}$. A $10 \mathrm{~cm}$ thick gravel layer was laid at the bottom of the pit to prevent water from eroding and destroying the soil and measurement benchmarks during irrigation. Three types of benchmarks were placed inside and outside the pit. The first type is the deep-buried steel pipe benchmarks, which is used to measure the collapsibility of loess at a specific depth. For example, the change for the benchmark at $8 \mathrm{~m}$ occurs only when the loess collapses below $8 \mathrm{~m}$. These benchmarks were placed inside the pit according to certain rules. Benchmarks 1-5 were arranged at equal intervals in a clockwise direction of a circle with a $1 \mathrm{~m}$ radius from the test pit center and were 2, 4, 6, 8, and $10 \mathrm{~m}$ deep. Benchmarks 6-10 were arranged in the radial direction of benchmarks 1-5, and the distance from the center of the circle was $2 \mathrm{~m}$ (see Figure 4(c)). The depths of the benchmarks on the same radius were the same. For example, benchmarks 1-6 have the same depth of $2 \mathrm{~m}$ and benchmarks 5 and 10 were $10 \mathrm{~m}$. Figure 4(a) shows that the deepburied steel pipe benchmark is composed of an unplasticized polyvinyl chloride (UPVC) pipe, steel pipe, steel bar, steel bottom base, and a $2 \mathrm{~m}$ steel ruler. The UPVC pipe with inner and outer diameters of $50 \mathrm{~mm}$ and $60 \mathrm{~mm}$, respectively, was placed into the Luoyang shovel with a diameter of $70 \mathrm{~mm}$ as a sleeve to prevent the shovel from collapsing. The sleeve was locked at the position of the orifice, whose upper end was $30 \mathrm{~cm}$ above the ground and the lower end was $30 \mathrm{~cm}$ above the bottom of the shovel. Inside the sleeve, the pole of the deep-buried steel pipe benchmark was made of steel pipe with an outer diameter of $25 \mathrm{~mm}$. The lower end of the steel pipe was sealed using a steel sheet with a diameter of $30 \mathrm{~mm}$ and acted as a bearing plate to prevent the steel pipe from sinking into the soil given its own weight. Consequently, the reliability of the measurement results was affected. The upper end of the pole was a steel bar with a length of $3 \mathrm{~m}$ and a diameter of $16 \mathrm{~mm}$. The steel bar was welded using a steel ruler with a length of $2 \mathrm{~m}$ and a scale of $1 \mathrm{~mm}$. This steel bar was used to indicate the collapsible amount of loess at the specific depth.

Another type of measurement mark in the test pit was the ground benchmark (benchmarks 11-35) which were used to measure the total collapsibility of loess. Similarly, these benchmarks were placed on two axes and two diagonal lines of the test pit in accordance with definite rules. Figure 4(c) shows that with the exception of benchmark 11, which was located at the center of the pit, the other benchmarks were located at each four six-quantile points and end points of the axis and diagonal lines. Given that the 25 benchmarks were set on the ground, they were all constructed similarly. This type of benchmark consisted of a steel bar, steel ruler, and a base. The steel bar with a length of $3 \mathrm{~m}$ and a diameter of $16 \mathrm{~mm}$ was anchored to a base of four layers of brick. The steel ruler with a length of $2 \mathrm{~m}$ and a scale of $1 \mathrm{~mm}$ was welded to the aforementioned steel bar. These 


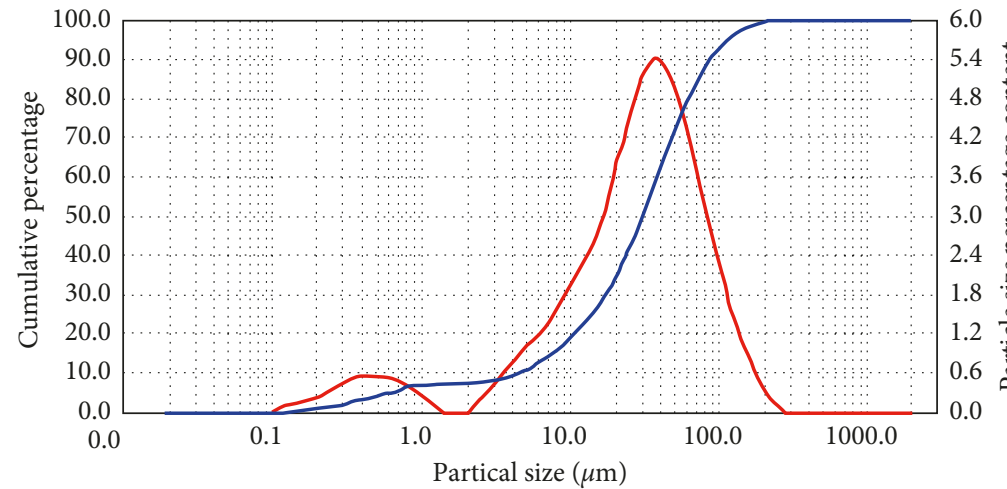

\begin{tabular}{lc}
\hline Particle size $(\mu \mathrm{m})$ & Percent content \\
\hline $0.000-0.107$ & 0.00 \\
$0.107-0.254$ & 1.20 \\
$0.254-0.605$ & 3.52 \\
$0.605-1.439$ & 2.17 \\
$1.439-3.422$ & 1.25 \\
$3.422-8.138$ & 7.35 \\
$8.138-19.35$ & 17.19 \\
$19.35-46.02$ & 34.82 \\
$46.02-109.4$ & 26.67 \\
$109.4-260.3$ & 5.83 \\
\hline
\end{tabular}

FIgURE 3: The grain diameter distribution map of Malan loess measured by laser particle size analyzer (Dandong Bettersize 2000).

TABle 1: Physical and mechanical properties of the three-level terraced loess in Jinjiaya village.

\begin{tabular}{lccccccccccc}
\hline $\begin{array}{l}\text { Number } \\
\text { of } \\
\text { samples }\end{array}$ & $\begin{array}{c}\text { Sample } \\
\text { depth } \\
(\mathrm{m})\end{array}$ & $\begin{array}{c}\text { Water } \\
\text { content } \\
(\%)\end{array}$ & $\begin{array}{c}\text { Dry } \\
\text { density } \\
\left(\mathrm{g} / \mathrm{cm}^{3}\right)\end{array}$ & $\begin{array}{c}\text { Specific } \\
\text { gravity } \\
\left(\mathrm{G}_{\mathrm{S}}\right)\end{array}$ & $\begin{array}{c}\text { Porosity } \\
\text { ratio }(\mathrm{e})\end{array}$ & $\begin{array}{c}\text { Size composition } \\
(\%)\end{array}$ & $\begin{array}{c}\text { Liquid } \\
\text { limit } \\
(\%)\end{array}$ & $\begin{array}{c}\text { Plastic } \\
\text { limit } \\
(\%)\end{array}$ & $\begin{array}{c}\text { Permeability } \\
\text { coefficient } \\
(\mathrm{cm} / \mathrm{s})\end{array}$ & $\begin{array}{c}\text { Collapsibility } \\
\text { coefficient }\end{array}$ \\
\hline 1 & 0.3 & 17.3 & 1.38 & 2.735 & 0.987 & 16.12 & 66.13 & 17.75 & 30.7 & 19.0 & $1.23 E-4$ \\
2 & 0.9 & 17.4 & 1.33 & 2.845 & 1.141 & 25.28 & 66.03 & 8.69 & 30.6 & 19.2 & $1.22 E-4$ \\
3 & 1.5 & 17.6 & 1.25 & 2.829 & 1.256 & 24.02 & 67.44 & 8.54 & 30.6 & 19.1 & $0.82 E-4$ \\
4 & 2.1 & 17.2 & 1.38 & 2.751 & 0.997 & 24.96 & 66.80 & 8.24 & 30.4 & 19.1 & $1.47 E-4$ \\
5 & 2.7 & 17.8 & 1.31 & 2.868 & 1.194 & 25.04 & 65.29 & 9.67 & 30.5 & 19.1 & $0.61 E-4$ \\
6 & 3.3 & 17.8 & 1.29 & 2.837 & 1.198 & 27.44 & 64.35 & 8.21 & 30.3 & 19.2 & $1.18 E-4$ \\
7 & 3.9 & 16.9 & 1.35 & 2.668 & 0.968 & 21.52 & 67.37 & 11.11 & 26.5 & 19.3 & $0.63 E-4$ \\
8 & 4.5 & 10.0 & 1.45 & 2.944 & 1.030 & 24.24 & 65.30 & 10.46 & 30.5 & 19.2 & 0.049 \\
9 & 5.1 & 19.6 & 1.38 & 2.779 & 1.014 & 23.97 & 67.74 & 8.29 & 30.5 & 19.2 & 0.094 \\
\hline
\end{tabular}

ground benchmarks were utilized to observe the total amount of collapsible loess in the test pit.

The third type of measurement mark was the ground benchmarks set outside the test pit. In contrast to the ground benchmarks in the test pit, these benchmarks outside the pit were simple because the irrigation collapse experiment only has a minimal effect on the outside area of the test pit. These measuring marks were arranged in four extension lines of the two pit axes. A total of 10 measuring marks on each extension line were arranged from near to far in accordance with the following spacing: $0.5,0.5,1,1,1.5,1.5,2,2,3$, and $3 \mathrm{~m}$ (see Figure 4(b)). The brick base and large iron nail were the main components of the ground benchmark. The top of the large iron nail was $1 \mathrm{~cm}$ above the ground, and the remainder was fixed on the base under the ground by cement mortar.

During the irrigation process, the three types of benchmarks were observed and tallied synchronously. The total duration of irrigation in this experiment was 40 days. Figure 5 shows the daily water consumption measured using the triangular weir. In the initial test stage, the changes in various benchmarks were observed using levels once a day. After half a month, the observation frequency was changed to once every 2 days and once every 5 days after one month. Finally, the test was terminated when the average daily collapsibility was below $1 \mathrm{~mm}$, thereby reaching the stability standard required by the code for building construction in collapsible loess regions.

The scanning samples made in the field were scanned with an electron microscope before and after humidification to acquire an improved understanding of the collapsibility of loess and reveal the microstructural changes in the loess collapsibility process. Similar to previous research methods, 18 scanning samples were prepared by semigel injection, and the samples before and after humidification were observed by SEM with the stepwise magnification method [44].

\section{Results}

To explain the collapsibility process of the loess, we selected the central point (11\#) of the test pit, maximum collapsibility point (27\#), and point with the maximum change in collapsibility at depths of $2,4,6,8$, and $10 \mathrm{~m}$ (corresponding to $1 \#, 2 \#, 3 \#, 4 \#$, and $10 \#$, respectively) to produce the collapsibility process curve, which can be called the settlementtime (S-T) curve (see Figure 6).

The collapsibility process curve in Figure 6(a) shows that all the curves were inverse S-shaped, and the entire collapsibility process was consistent regardless of depth. That is, a complete collapsibility process includes the initial reaction, intermediate collapsibility, and the final stable periods.

During the initial reaction period, the time and depth at which the benchmark at a specific loess depth begins to settle were nonlinear considering that the permeability of each layer obtained through the indoor variable head permeability test (TST-55) was different. The relationship between time and depth was related to the permeability of loess. Figure 7 shows that the $x$ and $y$ coordinates are used to represent permeability and depth, respectively, to reflect the 


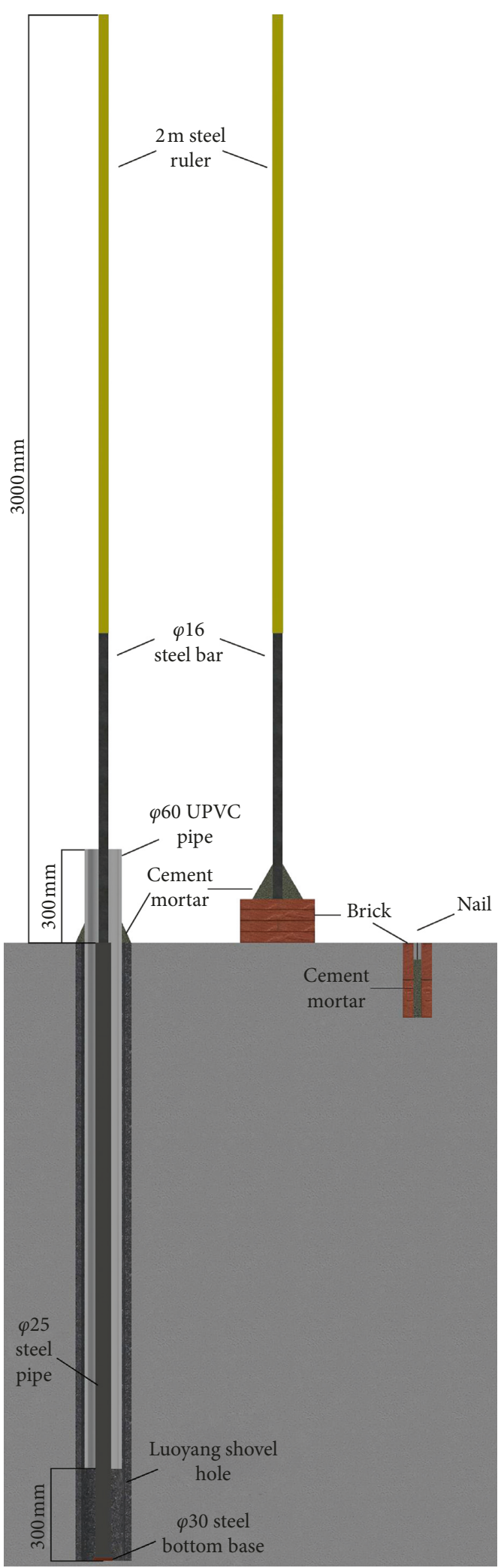

(a)

Figure 4: Continued. 


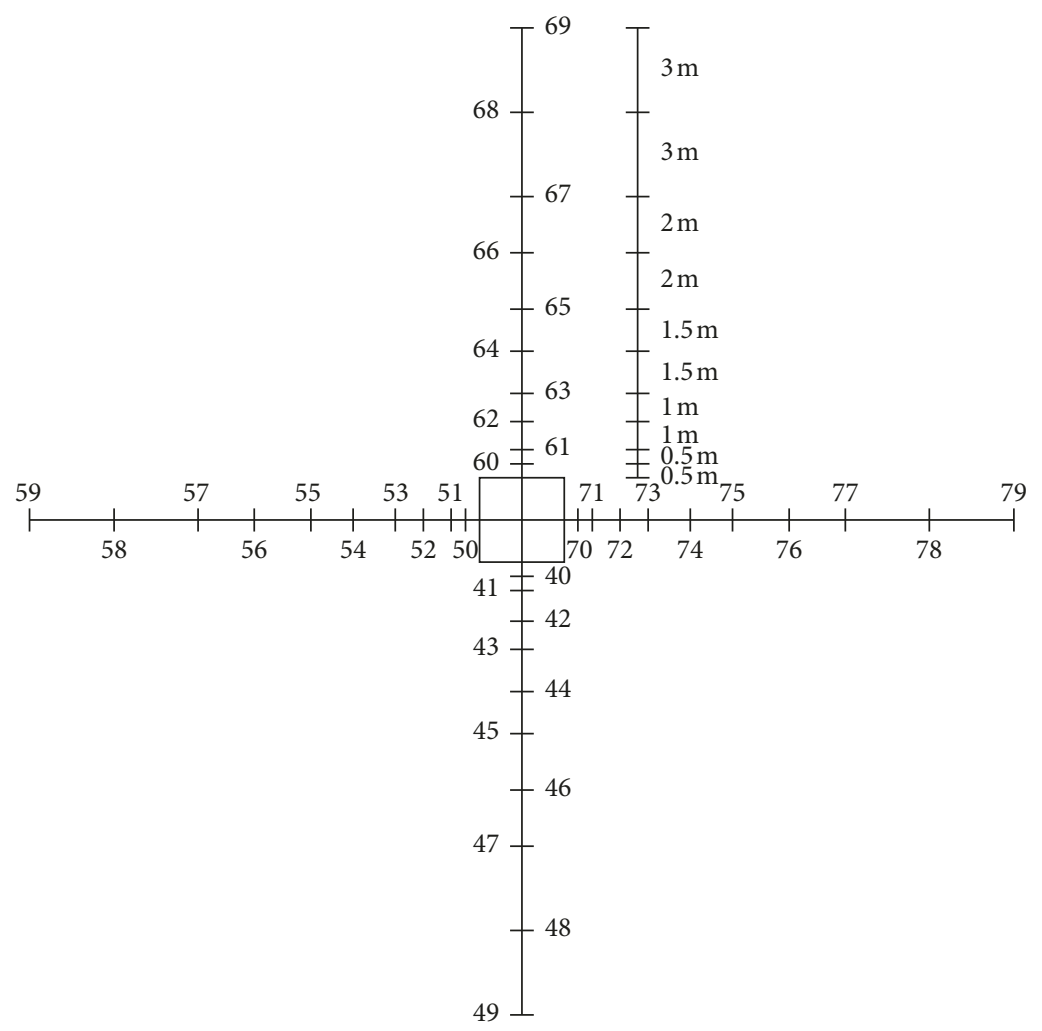

(b)

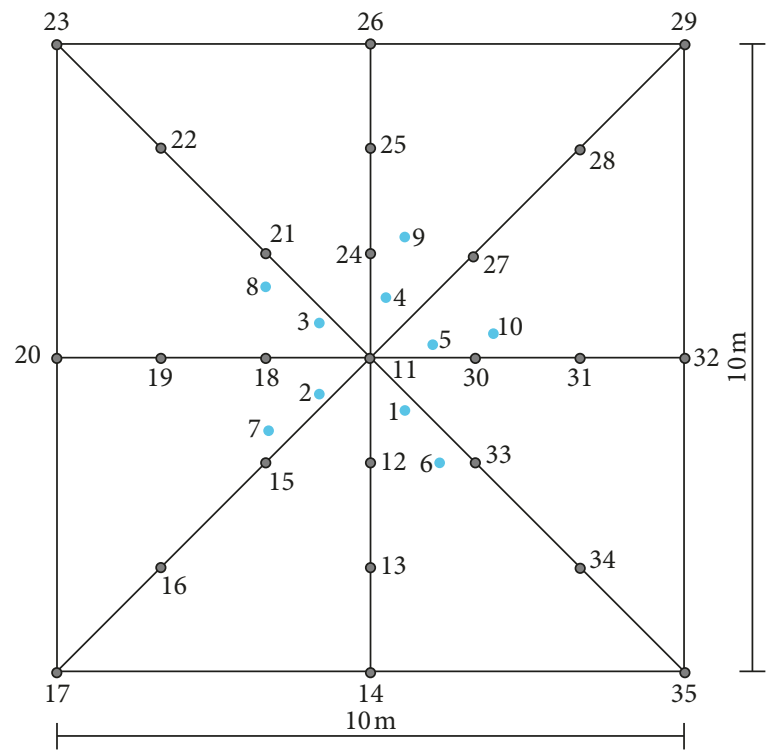

(c)

FiguRE 4: (a) The structure profile of three kinds of benchmarks for measuring collapsibility. (b) Layout of benchmarks outside the test pit. The four constant benchmarks (benchmarks 49, 59, 69, and 79) farthest from the center of test pit are generally to provide a standard for other benchmarks to be used to measure collapsibility. (c) Layout of benchmarks inside the test pit. The light blue ones are deep-buried steel pipe benchmarks used to measure collapsibility of loess at a specific depth, while other benchmarks are used to measure the total collapsibility inside the pit.

permeability of each loess layer visually. The gray scale size indicates the permeability coefficient of loess. The darker the colors, the faster the water can pass through the area. Light colors denote the difficulty for water to pass through.
Moreover, each rectangular area in the histogram represents the amount of water that can pass through this loess layer per unit time. From this figure, we could draw an evident conclusion that water can quickly infiltrate into the well- 


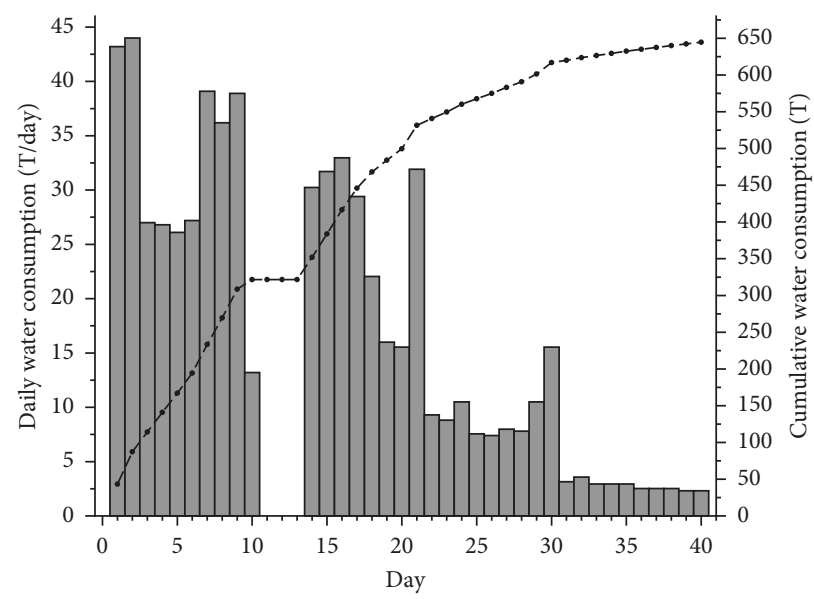

Figure 5: The daily and cumulative water consumption in 40-day irrigation experiments in Jinya Town. It should be noted that the irrigation process was interrupted for three days from the 11th to the 14th day due to equipment reasons.

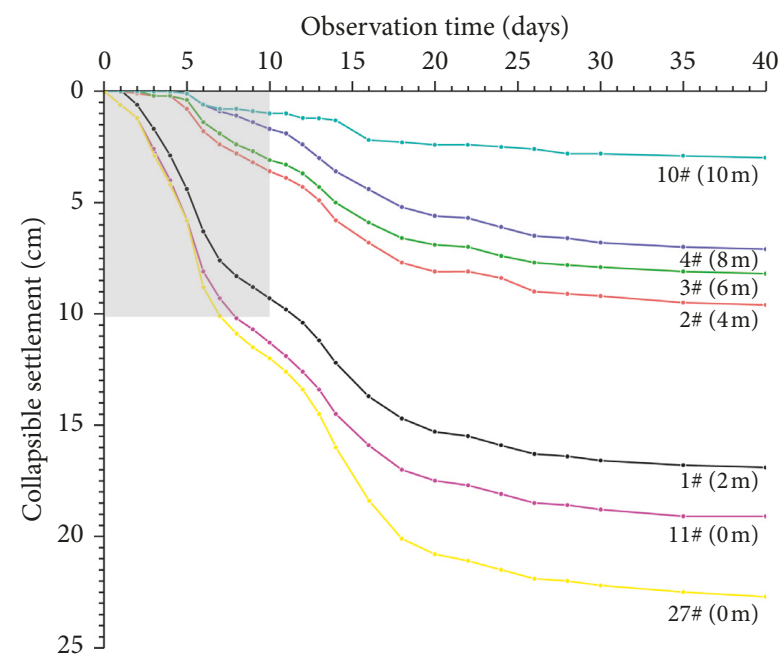

(a)

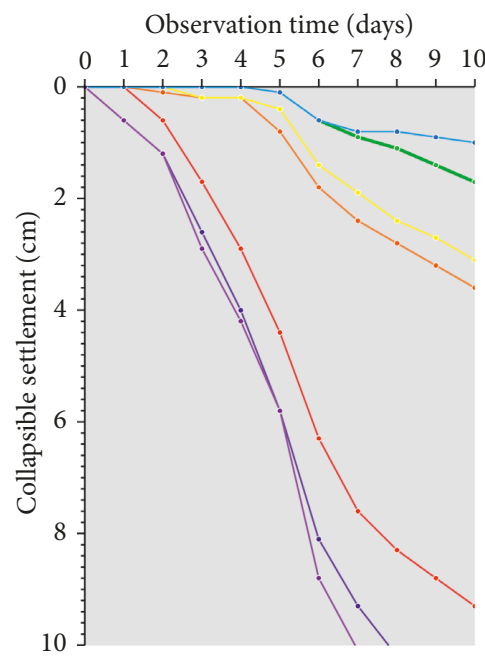

(b)

FIGURE 6: (a) The collapsibility process curve of typical benchmarks in the test pit. (b) Enlarged view of the previous 10 days' observation data.

permeable soil layer, which makes the structure of the soil change and the settlement occur rapidly. By contrast, the poor permeable soil layer will experience delays for the loess to begin to collapse. Figure 6(b) illustrates the difference in time when the settlement of each benchmark starts to change. Considering that benchmarks 11 and 27 were laid on the ground, the two benchmarks settled at the beginning of irrigation. By contrast, benchmark 1, which was laid at the depth of $2 \mathrm{~m}$, did not settle until the second day when the water reached this depth. Benchmark 10 at a depth of $10 \mathrm{~m}$ started sinking on the fifth day. Here, the permeability coefficient was measured using the permeameter in the laboratory. This value could only be used as a reference to indicate the relative permeability velocity of the discrete layers of loess. In the actual field, the permeability velocity was considerably higher than the measured indoors. On the fifth day of the field irrigation experiment, the water had infiltrated $10 \mathrm{~m}$ underground, which was unimaginable in accordance with the permeability coefficient measured in the laboratory. The duration of this period was brief: the longest is 2 days and the shortest was only 1 day. The settlement of all types of benchmarks was minimal and generally maintained within $0.6 \mathrm{~mm}$.

Given the increase in irrigation water and continuous infiltration of water into deep depths, the test pit eventually entered into the collapsibility period, during which the benchmarks decreased rapidly. Similar to the first period, the end time of this period (although unobservable) was delayed with the increase in depth. For example, benchmark 27 stabilized after a total settlement of $22.85 \mathrm{~cm}$ on the 28th day. By contrast benchmark 10 took another 4 days to stabilize.

Figures 6 and 8 show that differences were evident between this collapsibility process curve and the typical collapsibility process curve $[45,46]$. That is, the typical curve is a smooth curve at this period, whereas the curve shown in Figure 6(a) showed several twists and turns from the 11th to 


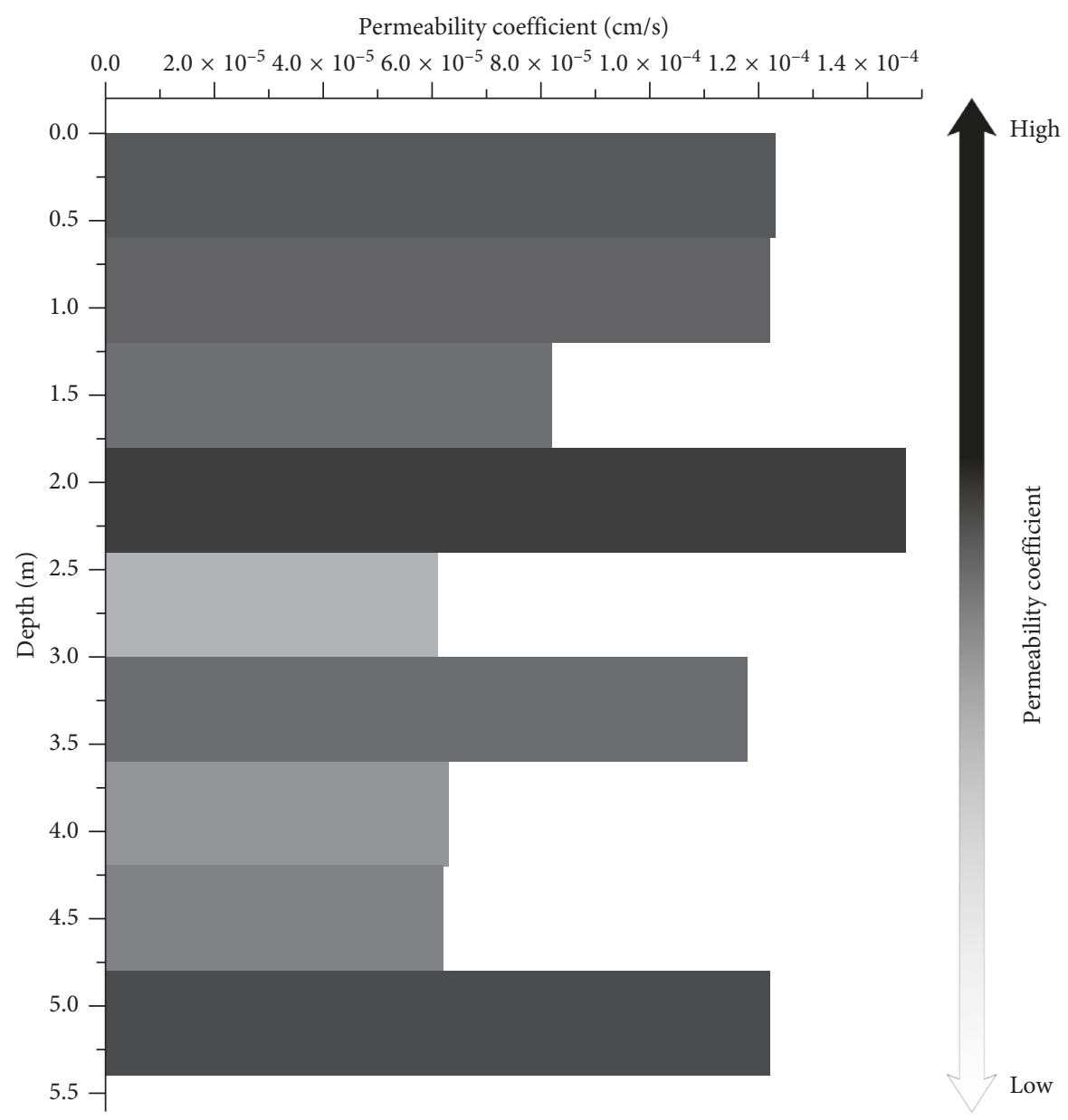

Figure 7: Vertical step diagram and gradient diagram of permeability coefficient. The gray scale indicates the permeability of loess in this layer. The darker the color, the faster the water can pass through the area.

the 14th day. The derivative of a smooth curve has only one extreme value (i.e., only one peak can be presented in Figure 8), but two peaks emerged on the 6th and 14th day. We carefully examined the abnormal phenomenon and compared the relationship between the irrigation and collapsibility processes. This abnormal phenomenon occurred on the 11th day to the 14th day of irrigation suspension because of a mechanical problem. Prior to the suspension of these irrigation experiments, the collapsibility velocity had shown a considerable downward trend. Furthermore, the collapsibility velocity had decreased from $0.8 \mathrm{~cm} /$ day to $0.6 \mathrm{~cm} /$ day from the 8th to the 9th day. However, the collapsibility velocity increased when irrigation was resumed and reached its peak on the 14th day, which was only 1 day later than the suspension of the irrigation. This interesting phenomenon has aroused our concern about multilevel collapsibility of loess because we have constantly believed that the loess is saturated during the entire irrigation process, particularly after the peak of the collapsibility velocity. Even if a short period of irrigation was suspended in this process, the trend of change in the collapsibility curve and rate will only fluctuate slightly. After the collapsibility velocity began to decline, the loess was nearly saturated because of the early infiltration. Even if the irrigation ended, the water content in the loess will remain relatively high to maintain the current decline rate of the collapsibility velocity. When irrigation was resumed, the two curves would continue to follow the previous trend of change and the collapsibility velocity would not increase slightly when the overall performance decreases. However, the results presented in Figure 8 were unexpected. When the collapsibility velocity approximated the velocity in the final stable period, given the resumption of irrigation, the collapsibility velocity increased again and reached a new peak on the 14th day, which was only one day after the resumption of irrigation.

The comparison results of the two peaks indicated that the collapsibility velocity of loess in this region decreased rapidly within 3 days after reaching the first peak but tended to be stable and approximate the velocity of the final stable period. However, the collapsibility velocity took 8 days to stabilize after the second peak was reached. This phenomenon was also contrary to our expectations. We believed that after the collapse of the previous irrigation period, the loess structure will become more stable than that in the initial state (we called the improved structure) and the improved structure will remain unchanged during reirrigation. Thus, the time required to stabilize will be shorter than before. The benchmarks took longer to 


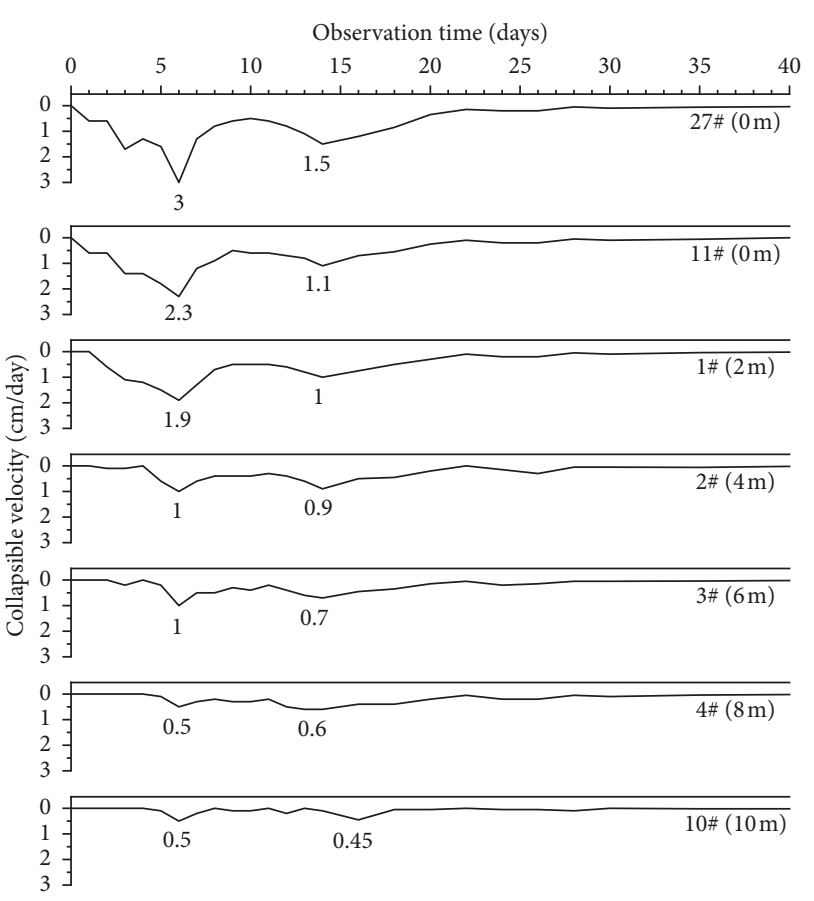

FIgURE 8: The collapsibility velocity of each benchmark. Because the irrigation process was interrupted for three days, the collapsibility velocity curve of the irrigation appears different from the typical curve, that is, there is a peak value before and after the interruption. The second peak is smaller than the first one, and the difference between these two peaks decreases with the increase of depth.

stabilize after the secondary collapse than it did after the first collapse because the continued loess settlement may be closely related to the change in loess structure during irrigation. Under the condition of lower water content, the loess structure will be relatively stable and the cementing effect between particles which formed spaced pores is strong. This type of pores easily forms porous media with enhanced permeability. Irrigation water may infiltrate downward faster in such media than in the compact structure. Thus, once a large amount of irrigation water is encountered, the connection between particles will be reduced under the action of loess water sensitivity and the overhead pore will be destroyed. In addition, the internal structure will collapse, and the broken structure will be filled in the original position of the overhead pore. The collapsibility velocity of this type of collapsibility mode increases and decreases rapidly. Given that loess in nature constantly develops toward a stable state, these changes were macroscopically realized as a rapid collapse in the foundation. After a collapse and maintaining a relatively high water content, the spaced pores in the loess were destroyed. Thus, a small space for collapsibility is identified in the subsequent irrigation. Macroscopically, the accumulated settlement of the foundation at this time was small and the collapsibility velocity was slow.

The final stable period exhibited in Figure 6 is the same as that in the typical curve. The curve is close to the horizontal direction, and the foundation gradually stabilizes.

In the SEM experiment, six representative images with good image quality were selected for comparative analysis. Figure 9 shows the microstructural comparison of the same sample at the same position before and after humidification. On a microscale, the three deformation types of the loess particles are movement, dissolution, and reunion. The change of aggregates A3 and A5 is a typical representative of particle movement. In the case that the basic shape, size, and relative angle relationship of triangle T1 remain unchanged, the aggregate of A5 moves $50^{\circ}$ upward, while the original position of the aggregate is occupied by the aggregate of $\mathrm{A} 3$, thereby forming a new pore structure. Similarly, aggregate $\mathrm{A} 1$ and particles $\mathrm{P} 1$ and P3 also change their state through this deformation mode. Dissolved substances in loess generally refer to clay particles cemented around silt and sand grains. Some watersoluble minerals dissolve under the action of water, which disperses the previously cemented particles or aggregates. For example, particles P5 and P6 partially dissolve or disappear after humidification. Meanwhile, the undissolved parts also have a sense of stripping with the originally connected particles. The dissolved clay will reunite in due course and form new particles or cement other particles. Under the influence of these three deformation types, the loess will develop toward the overall stability. However, new macro or spaced pores will be formed in the local areas of the loess, thereby providing the possibility for the next collapse.

\section{Discussion}

During this irrigation process, two inverse S-shaped curves were similar to two typical collapsibility curves that were connected one after the other. Compared with the typical curve, the second collapse in this observation data was originally a continuation of the first peak. The loess 


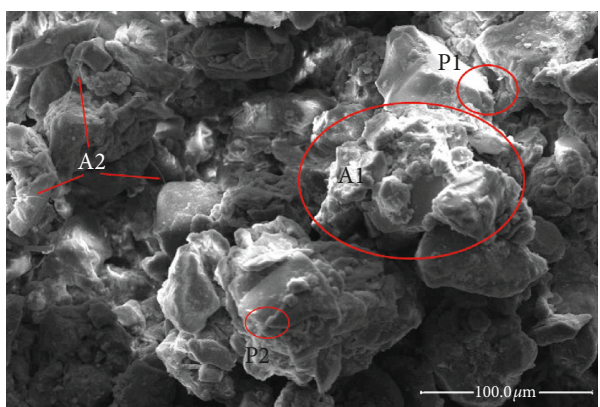

(a)

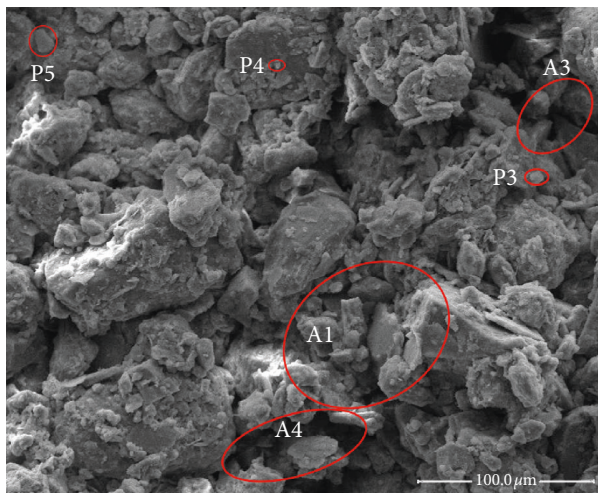

(c)

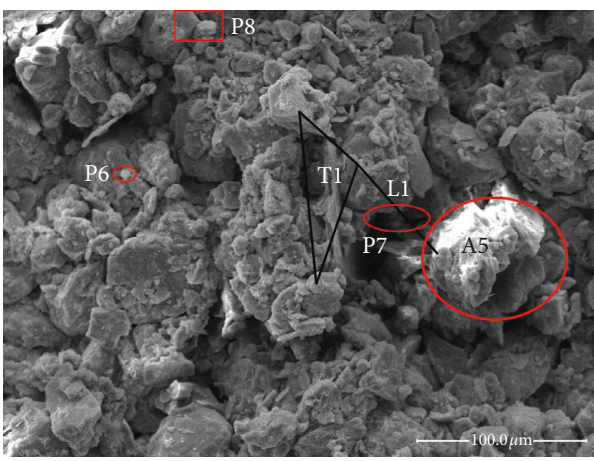

(e)

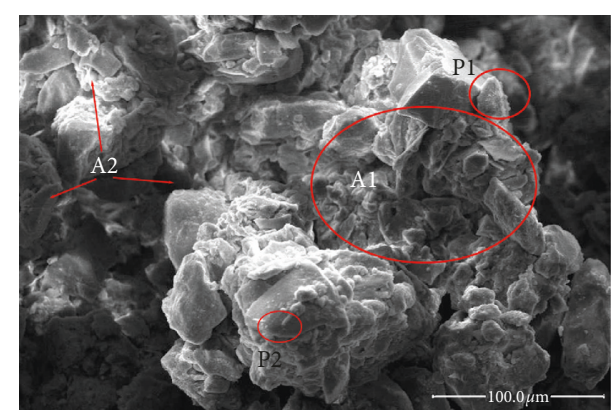

(b)

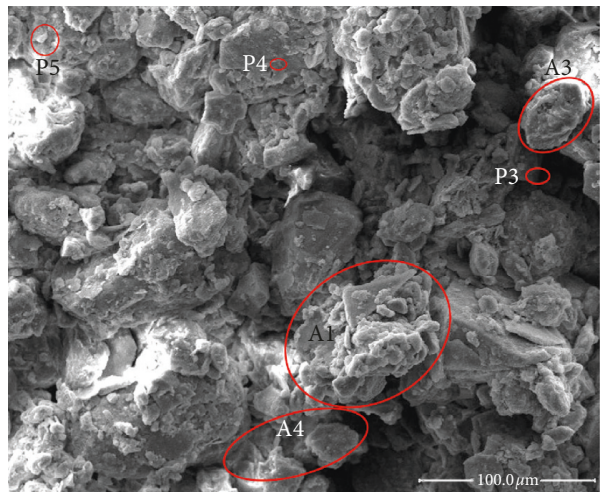

(d)

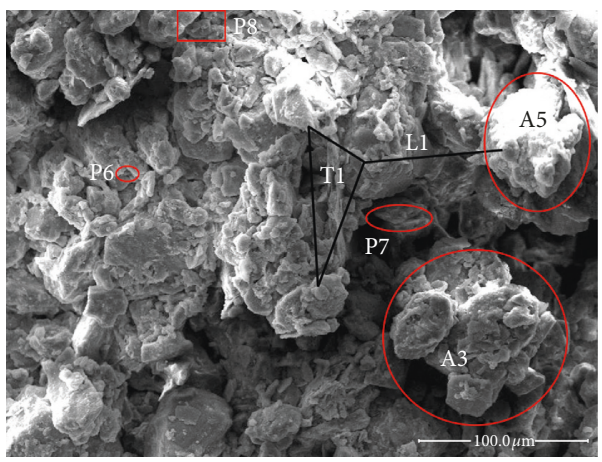

(f)

FIGURE 9: SEM images at the same positions before (a, c, e) and after (b, d, f) humidification.

simultaneously lost part of its water and created a second collapsibility because of the water suspension in the middle of 3 days. This finding indicated that the change of water content has a profound influence on the collapsibility of loess. The water content of the loess affected its structure, and the structural change led to the deformation change of loess. Therefore, the deep reason for the collapsibility of loess is its internal structure change, regardless of whether such a change is related to water, mineral species, and particle morphology. The three deformation decomposition types enable the formation of new macropores in the loess interior for the next collapsibility. Therefore, the collapsibility of loess may be a dynamic process related to time and water content. Even if the loess can eventually achieve stability and eliminate collapsibility, the previous dynamic collapse processes should continue to be considered.

\section{Conclusion}

We provide the following conclusions on the bases of previous and current irrigation experiments.

(1) The collapsibility of loess is a dynamic process. When heavy rainfall or irrigation occurs, the pore structure inside the loess will be destroyed under the action of water sensitivity. When rainfall or irrigation stops, new pores will eventually be formed with the water content decrease in loess, thereby providing conditions for the next collapse. 
(2) In addition to the natural state, the collapsibility of loess could not be completely eliminated by itself, even under irrigation conditions.

(3) Collapsible loess may result many times, particularly during rainfall, large-scale irrigation, or even continuous irrigation.

Although the accidental event of this irrigation experience had made us realize the multilevel collapsibility of loess, to improve our understanding of the collapsibility of loess, further research is required on mechanism of multilevel collapsibility of loess to guide us in applying engineering geology effectively.

\section{Data Availability}

The collapse and permeability coefficient data used to support the findings of this study are included within the article.

\section{Conflicts of Interest}

The authors declare that there are no conflicts of interest regarding the publication of this article.

\section{Acknowledgments}

We would like to thank the villagers of Jinjiaya for their help. Without their help, this experiment would not have been successful. This study was financially supported by the fund of Key Projects of National Natural Science Foundation of China (grant no. 41630634). The Innovation Group and Major Research Project of Education Department of Guizhou Province (grant nos. QJH-KY (2016) 054 and QJHKY (2016) 055) and Scientific Innovation Practice Project of Postgraduates of Chang'an University (300103002025) also supported this study.

\section{References}

[1] A. M. Assallay, C. D. F. Rogers, and I. J. Smalley, "Formation and collapse of metastable particle packings and open structures in loess deposits," Engineering Geology, vol. 48, no. 1-2, pp. 101-115, 1997.

[2] X. H. Bai, F. L. Ma, M. Wang, and J. G. Jia, Micro-Structure and Collapsibility of Loess in China, CRC Press-Taylor \& Francis Group, Boca Raton, FL, USA, 2015.

[3] X. Li and L. Li, "Quantification of the pore structures of Malan loess and the effects on loess permeability and environmental significance, Shaanxi Province, China: an experimental study," Environmental Earth Sciences, vol. 76, no. 15, p. 523, 2017.

[4] L. Barden, A. McGown, and K. Collins, "The collapse mechanism in partly saturated soil," Engineering Geology, vol. 7, no. 1, pp. 49-60, 1973.

[5] M. Momeni, A. Shafiee, M. Heidari, M. K. Jafari, and M. R. Mahdavifar, "Evaluation of soil collapse potential in regional scale," Natural Hazards, vol. 64, no. 1, pp. 459-479, 2012.

[6] X. Shao, H. Zhang, and Y. Tan, "Collapse behavior and microstructural alteration of remolded loess under graded wetting tests," Engineering Geology, vol. 233, pp. 11-22, 2018.
[7] P. Sun, M. Zhang, L. Zhu, Q. Xue, and W. Hu, "Typical case study of loess collapse and discussion on related problems," Geological Bulletin of China, vol. 32, no. 6, pp. 847-851, 2013, in Chinese.

[8] Y. Leng, J. Peng, Q. Wang, Z. Meng, and W. Huang, "A fluidized landslide occurred in the Loess plateau: a study on loess landslide in South Jingyang tableland," Engineering Geology, vol. 236, pp. 129-136, 2017.

[9] X. Lei, "The hazards of loess landslides in the Southern tableland of Jingyang County, Shaanxi and their relationship with the channel water into fields," Journal of Engineering Geology, vol. 3, no. 1, pp. 56-64, 1995, in Chinese.

[10] K. Terzaghi, Theoretical Soil Mechanics, John Wiley \& Sons, New York, NY, USA, 1943.

[11] E. Derbyshire, T. Dijkstra, and I. J. Smalley, Genesis and Properties of Collapsible Soils, Springer, Dordrecht, Netherlands, 1995.

[12] Q. Huang, "Discussion on evaluation of collapsible loess foundation," China Civil Engineering Journal, vol. 9, no. 2, pp. 37-42, 1963.

[13] G. Tu, "The sensitivity of the self weight collapsibility of the loess foundation," Geotechnical Investigation \& Surveying, vol. 8, no. 2, pp. 36-39, 1980, in Chinese.

[14] SCSI, "The characteristics of loess and loess-like soil in China and the evaluation method of its collapsibility and bearing capacity," Geotechnical Investigation \& Surveying, vol. 1, no. 3, pp. 1-27, 1973, in Chinese.

[15] E. Y. Huang, Lime as Stabilizing Agent for Loess Soils, University of Michigan, Ann Arbor, MI, USA, 1953.

[16] J. H. Dudley, "Review of collapsing soils," Journal of Soil Mechanics \& Foundations Division, vol. 96, no. 3, pp. 925-947, 1970.

[17] B. D. v. t. Woudt, "Particle coatings affecting the wettability of soils," Journal of Geophysical Research, vol. 64, no. 2, pp. 263-267, 1959.

[18] X. Lei, "The pore type and collapsibility of loess in China," Scientia Sinica (Episodes B), vol. 17, pp. 1309-1318, 1987, in Chinese.

[19] G. Gao, "Microstructure of loess soil in China relative to geographic and geology environment," Acta Geologica Sinica, vol. 3, pp. 265-270, 1984, in Chinese.

[20] M. R. Cox and M. Budhu, "A practical approach to grain shape quantification," Engineering Geology, vol. 96, no. 1-2, pp. 1-16, 2008.

[21] N. Prakongkep, A. Suddhiprakarn, I. Kheoruenromne, and R. J. Gilkes, "SEM image analysis for characterization of sand grains in Thai paddy soils," Geoderma, vol. 156, no. 1-2, pp. 20-31, 2010.

[22] M. Vidal, M. Ostra, N. Imaz, E. García-Lecina, and C. Ubide, "Analysis of SEM digital images to quantify crack network pattern area in chromium electrodeposits," Surface and Coatings Technology, vol. 285, pp. 289-297, 2016.

[23] D. Miao and X. Bai, "Microstructure of soil using SEM images based on Matlab," Hydrogeology \& Engineer Geology, vol. 41, no. 6, pp. 141-146, 2014, in Chinese.

[24] L. Hao and J. Lu, "A method for the calculating of clay minerals content of soil," Chinese Journal of Soil Science, vol. 37, no. 3, pp. 456-459, 2006, in Chinese.

[25] Z. Guo, X. Li, Y. Chen, J. Luo, b. Hong, and L. Wang, "Analysis of clay minerals in collapsible loess with SEM-EDS," Journal of Engineering Geology, vol. 24, no. 5, pp. 899-906, 2016.

[26] S. K. Vanapalli, D. G. Fredlund, and D. E. Pufahl, "The Influence of soil structure and stress history on the soil-water 
characteristics of a compacted till," Géotechnique, vol. 51, no. 6, pp. 573-576, 1999.

[27] V. Olphen, "An introduction to clay colloid chemistry," Soil Science, vol. 97, no. 4, p. 290, 1991.

[28] G. Gao, "A structure theory for collapsing deformation of loess soils," Chinese Journal of Geotechnical Engineering, vol. 12 , no. 4 , pp. 1-10, 1990, in Chinese.

[29] D. G. Fredlund and N. R. Morgenstern, "Stress state variables for unsaturated soils," Journal of the Geotechnical Engineering Division, vol. 103, no. 5, pp. 447-466, 1977.

[30] J. H. F. Pereira and D. G. Fredlund, "Volume change behavior of collapsible compacted gneiss soil," Journal of Geotechnical and Geoenvironmental Engineering, vol. 126, no. 10, pp. 907-916, 2000.

[31] Z. H. Chen, D. G. Fredlund, and J. K. Gan, "Overall volume change, water volume change, and yield associated with an unsaturated compacted loess," Canadian Geotechnical Journal, vol. 36, no. 2, pp. 321-329, 1999.

[32] P. Li, S. Vanapalli, and T. Li, "Review of collapse triggering mechanism of collapsible soils due to wetting," Journal of Rock Mechanics and Geotechnical Engineering, vol. 8, no. 2, pp. 256-274, 2016.

[33] M. Sillanpää and L. R. Webber, "The effect of freezing-thawing and wetting-drying cycles on soil aggregation," Canadian Journal of Soil Science, vol. 41, no. 2, pp. 182-187, 1961.

[34] E. J. Chamberlain and A. J. Gow, "Effect of freezing and thawing on the permeability and structure of soils," Developments in Geotechnical Engineering, vol. 13, no. 1-4, pp. 73-92, 1979.

[35] C. Dan and L. Jian-Kun, "Review of the influence of freezethaw cycles on the physical and mechanical properties of soil," Sciences in Cold and Arid Regions, vol. 5, no. 4, pp. 457-460, 2013.

[36] B. D. Kay and A. R. Dexter, "The influence of dispersible clay and wetting/drying cycles on the tensile strength of a redbrown earth," Soil Research, vol. 30, no. 3, pp. 297-310, 1992.

[37] K. A. Czurda and M. Hohmann, "Freezing effect on shear strength of clayey soils," Applied Clay Science, vol. 12, no. 1-2, pp. 165-187, 1997.

[38] S. L. Houston, W. N. Houston, C. E. Zapata, and C. Lawrence, "Geotechnical engineering practice for collapsible soils," Geotechnical and Geological Engineering, vol. 19, pp. 333-355, 2001.

[39] H. Bing and P. He, "Experimental investigations on the influence of cyclical freezing and thawing on physical and mechanical properties of saline soil," Environmental Earth Sciences, vol. 64, no. 2, pp. 431-436, 2011.

[40] G. Li, W. Ma, F. Wang et al., "Processes and mechanisms of multi-collapse of loess roads in seasonally frozen ground regions: a review," Sciences in Cold and Arid Regions, vol. 7, no. 4, pp. 456-468, 2015.

[41] X. Hu, B. Pan, H. Su, C. An, and T. Zhou, "Terrace formation age and river incision mechanism of Wanchuan River," Scientia Geographica Sinica, vol. 27, no. 6, pp. 808-813, 2007, in Chinese.

[42] Y. Zhu and Z. Chen, "A new method of studying collapsibility of loess," Frontiers of Architecture and Civil Engineering in China, vol. 3, no. 3, pp. 305-311, 2009.

[43] H. Sadeghi, M. Kiani, M. Sadeghi, and F. Jafarzadeh, "Geotechnical characterization and collapsibility of a natural dispersive loess," Engineering Geology, vol. 250, pp. 89-100, 2019.

[44] X. Z. Zhang, Y. D. Lu, X. Li, Y. C. Lu, and W. S. Pan, "Microscopic structure changes of malan loess after humidification in South Jingyang plateau, China," Environmental Earth Sciences, vol. 78, no. 10, p. 287, 2019.

[45] J. Feda, "Collapse of loess upon wetting," Engineering Geology, vol. 25, no. 2-4, pp. 263-269, 1988.

[46] D. A. Sun and H. Matsuoka, "Collapse behavior of compacted clays in suction-controlled triaxial tests," Geotechnical Testing Journal, vol. 27, no. 4, pp. 362-370, 2004. 


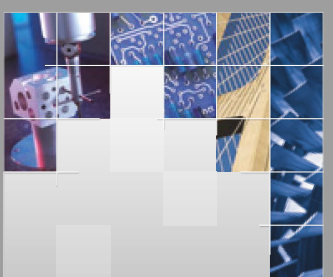

\section{Enfincering}
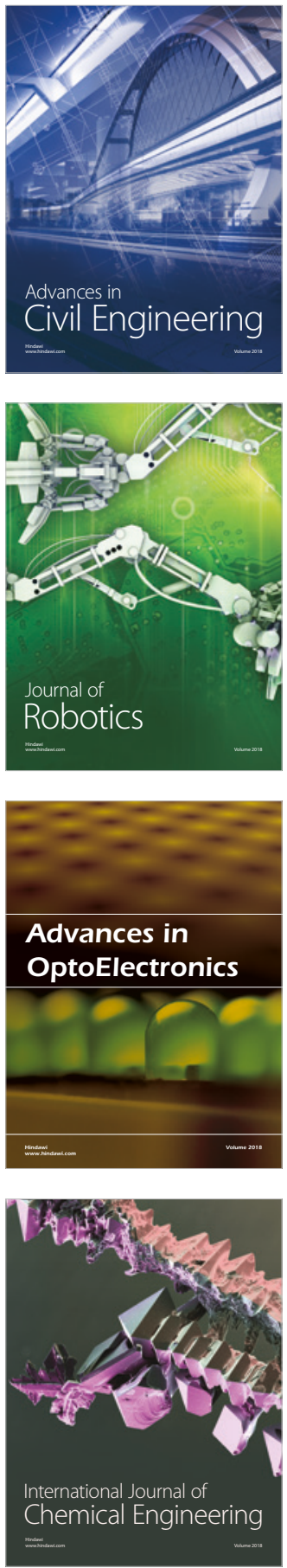

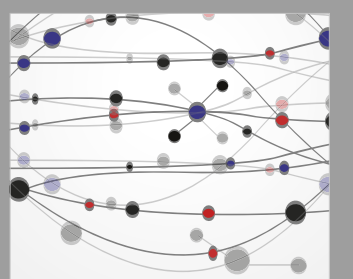

\section{Rotating \\ Machinery}

The Scientific World Journal

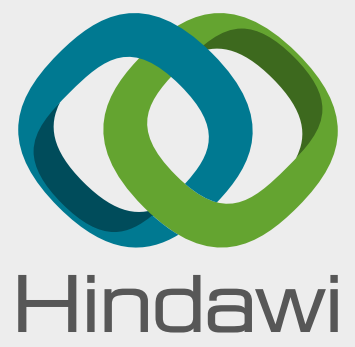

Submit your manuscripts at

www.hindawi.com
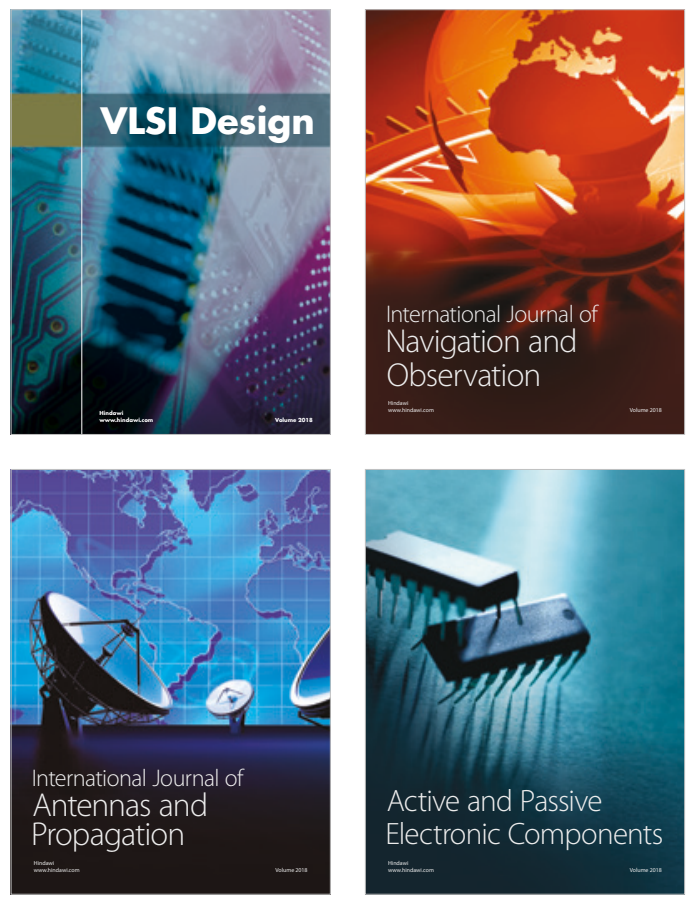
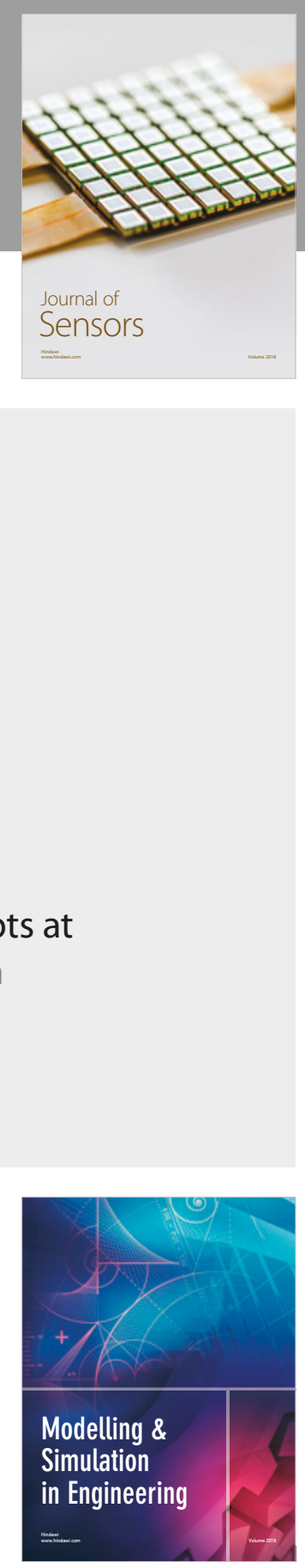

\section{Advances \\ Multimedia}
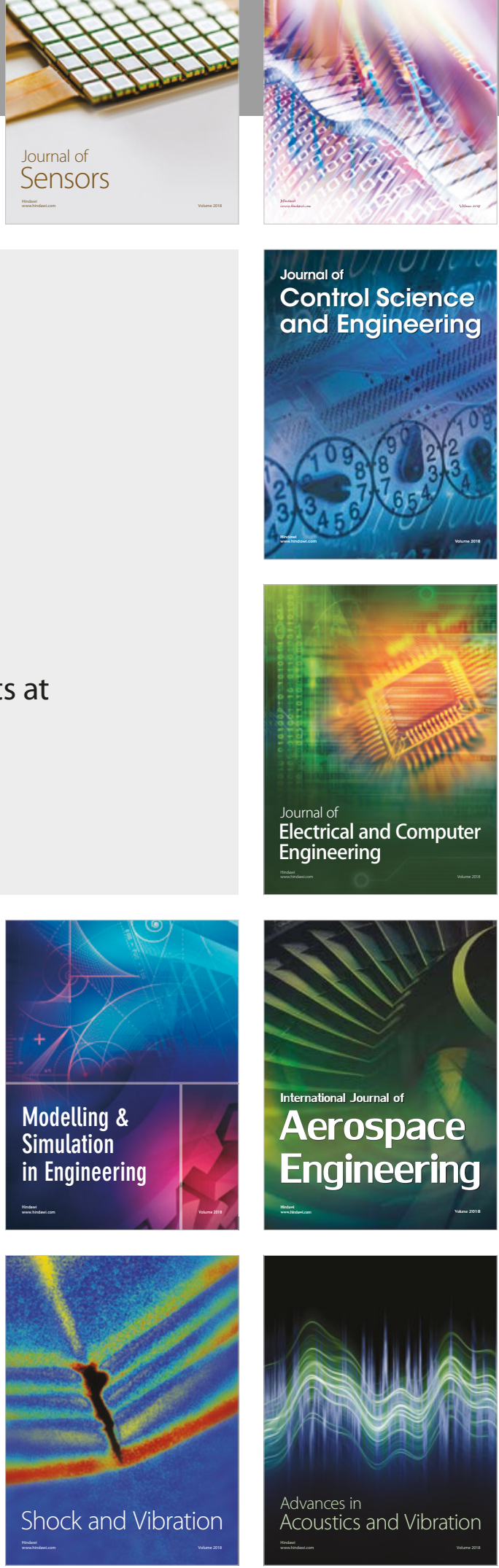